\title{
Real-time quantification of microbial degradation of copepod fecal pellets monitored by isothermal microcalorimetry
}

\author{
Søren N. Olsen, Peter Westh, Benni W. Hansen* \\ Department of Life Sciences and Chemistry, Roskilde University, PO Box 260, 4000 Roskilde, Denmark
}

\begin{abstract}
This study introduces isothermal microcalorimetry as a method to describe microbial degradation of copepod fecal pellets through measurements of the metabolic heat-flow produced by the degrading microbial community. We monitored the heat-flow for 20 to $24 \mathrm{~h}$ from samples of 300 to 1500 fecal pellets from a laboratory-cultivated calanoid copepod, Acartia tonsa Dana, fed on the chryptophyte Rhodomonas salina in excess. The microbes grew at 0.095 to $0.24 \mathrm{~h}^{-1}$. Specific degradation rates were calculated using 3 different literature values of the carbon:volume ratio of fecal pellets. The mean \pm SD specific degradation rates, $R_{\mathrm{d}}$, were estimated at $0.023 \pm 0.015 \mathrm{~h}^{-1}$ (for

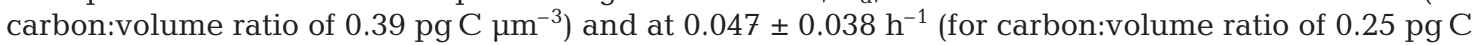
$\mu^{-3}$ ), defined as the proportion of fecal pellet carbon completely oxidised to $\mathrm{CO}_{2} \mathrm{~h}^{-1}$. The lowest car-

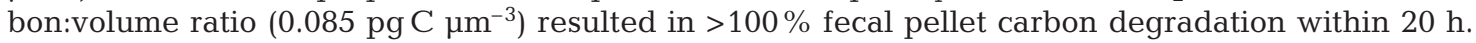
These degradation rates are very high, presumably reflecting a fully active bacterial population. The limiting factor for microbial growth was not inorganic nutrients ( $\mathrm{N}$ and $\mathrm{P}$ ), but labile dissolved organic carbon (DOC). We compared heat-flow in situations with and without oxygen, and found it to be 1 order of magnitude lower under anoxic conditions. This indicates the presence of anaerobic or facultative bacteria associated with the fecal pellets. Possible applications of the methodology are discussed.
\end{abstract}

KEY WORDS: Copepod fecal pellets - Degradation - Microbial community · Isothermal microcalorimetry

Resale or republication not permitted without written consent of the publisher

\section{INTRODUCTION}

The importance of marine copepods as a link between primary producers and higher trophic levels has long been recognized. However, there is also growing evidence that marine copepods play an important role in the heterotrophic microbial community by providing substrate in the form of dissolved organic carbon (DOC) or particulate organic carbon (POC), either by sloppy feeding or through excretion of fecal pellets (Jumars et al. 1989, Lampitt et al. 1990, Martens \& Krause 1990, Hygum et al. 1997, Urban Rich 1999, Møller et al. 2003). A recent review by Turner (2002) gives a comprehensive overview of aspects in the production and fate of copepod fecal pellets.
During food conversion by copepods, approximately one-third of their ingested organic carbon is released as fecal pellets (Smetacek 1980, Kiørboe et al. 1985, Jumars et al. 1989, Noji 1991, Møller \& Nielsen 2001), which either sink to the sediment (to the benefit of the benthic community) or are remineralized in the pelagic (e.g. Martens \& Krause 1990, Butler \& Dam 1994). Studies of the vertical flux of POC to the benthic community have shown that the size of fecal pellets is important for the rate of decomposition (see Turner 2002 and references therein). Thus, fecal pellets produced from small copepods are believed to be decomposed in the epipelagic, thereby providing substrates for the microbial loop (Smetacek 1980, Bathmann et al. 1987, Feinberg \& Dam 1998). In order to estimate the quantitative contribution of fecal pellets to the vertical 
flux of POC to the benthic community, reliable data on the degradation rates of fecal pellets and on DOC diffusion rates from the fecal pellets are essential.

Degradation rates of fecal pellets have been studied using several methods, including video measurements of decreasing fecal pellet volume (Hansen et al. 1996) and isotopic labeling of bacterial growth (Urban-Rich 1999, Møller et al. 2003, Thor et al. 2003, Olesen et al. 2005). Rates of degradation of fecal pellets from the large oceanic copepod Calanus hyperboreus have been reported to be $6 \% \mathrm{~d}^{-1}$ (carbon released as $\mathrm{CO}_{2}$; Urban-Rich 1999). Studies of fecal pellets from the small neritic copepod Acartia tonsa have reported degradation rates around $10 \% \mathrm{~d}^{-1}$ (Lee \& Fisher 1992) to $9-19 \% \mathrm{~d}^{-1}$ (Thor et al. 2003) $\left({ }^{14} \mathrm{C}\right.$-loss from particulate fecal pellets). At excess food concentrations of Rhodomonas baltica, Hansen et al. (1996) found that more than $90 \%$ of the fecal pellets were degraded within the first $24 \mathrm{~h}$ (video measurements of decreasing fecal pellet volume).

The diffusion of DOC from fecal pellets produced by Acartia tonsa has been shown to be quite rapid: more than $50 \%$ of the total organic carbon (TOC) is suggested to be lost from the pellets of $A$. tonsa during the initial handling of the pellets (Thor et al. 2003). The loss of DOC from fecal pellets produced by Calanus finmarchicus has been reported to be as high as $28 \%$ within 15 min (Møller et al. 2003). Model calculations even suggest that diffusive loss exceeds $50 \%$ of the initial TOC within a time frame as short as 5 min (Jumars et al. 1989). This emphasizes that handling time before measurements must be minimal (sensu Thor et al. 2003).

In the present study, we adopted a calorimetric procedure for the study of fecal pellet degradation. Calorimetry has only been applied in a few studies concerning aquatic microbial communities (e.g. Pamatmat et al. 1981, Tornblom 1995, Mukhanov et al. 2003, 2004, Pamatmat 2003). It has been used to estimate energy budgets of an algal mat community from a hypersaline lake (Mukhanov et al. 2004) and to compare the productivity of 2 different marine ecosystems characterized by different degrees of pollution and eutrophication (Mukhanov et al. 2003). Furthermore anaerobic microbial metabolism has been measured by calorimetry in a variety of different systems, e.g. in batch cultures (Duboc et al. 1999, and references therein) and marine sediments (Pamatmat et al. 1981, Pamatmat 2003).

The use of calorimetry in the present study was motivated by the significant increase in sensitivity provided by a number of recently developed commercial instruments. These technical improvements have also made calorimetry an interesting approach for samples of low biomass. Thus, the method provides real-time information on metabolic heat production without the need of probes or special sample treatment, and can be applied to both oxic and anoxic processes. A particular advantage of the method is that the experimental parameter which is measured in isothermal calorimetry is the flow of heat (in $\mathrm{J} \mathrm{s}^{-1}$ or $\mathrm{W})$ exchanged between the calorimetric vessel and its surroundings. The metabolic activity is proportional to this heat-flow and hence quantified directly by the calorimetric signal (Battley 1987, Stocker \& Marison 1989, Gustafsson 1991, Stocker et al. 1993, Larsson \& Gustafsson 1999). This is in contrast to other methods, such as respirometry, which is obviously restricted to oxic processes. In addition, metabolic rates measured by respirometry are derived from the difference between sequential registrations-often involving only small relative changes. Using isothermal calorimetry, we have characterized microbial growth rates and their limiting factors in degrading fecal pellets from the cultivated calanoid copepod Acartia tonsa. We have also used the calorimetric data in a first attempt to estimate degradation rates based on the enthalpy arising from combustion of biological biomass (Duboc et al. 1999), and have compared the heat-flow under oxic and anoxic conditions.

\section{MATERIALS AND METHODS}

Production of fecal pellets. Fecal pellets were collected from laboratory cultures of the calanoid copepod Acartia tonsa fed on the chryptophyte Rhodomonas salina in excess at $17^{\circ} \mathrm{C}$ and 30 salinity according to Støttrup et al. (1986). $R$. salina were cultivated in logarithmic-growth cultures in $\mathrm{B}_{1}$ media (Hansen 1989) at $120 \mu \mathrm{E} \mathrm{m} \mathrm{m}^{-2} \mathrm{~s}^{-1}$ photosynthetically active radiation. Copepods were continuously cultivated in 701 tanks and fed $R$. salina in excess. Copepodite Stages IV and V and adults were collected by gently filtering the tank contents through a $250 \mu \mathrm{m}-$ mesh screen, transferred to a 11 beaker with $R$. salina at a concentration of 50 to 100000 cells ml${ }^{-1}$, and allowed to graze for approximately $1 \mathrm{~h}$. Copepod density was approximately 1000 ind. $\mathrm{l}^{-1}$. After grazing, the bottom water of the beaker was collected with a mouth pipette, and filtered through 3 consecutive filters with mesh sizes of 100,70 and $45 \mu \mathrm{m}$, respectively. This resulted in $>80 \% \mathrm{v} / \mathrm{v}$ fecal pellets on the $45 \mu \mathrm{m}$ filter. The remaining $\sim 20 \%$ comprised primarily eggs and amorphous detritus. The pellets were transferred from the filter to a sterile Petri dish with $0.2 \mu \mathrm{m}$-filtered, stored seawater (i.e. seawater kept in the dark for 3 mo prior to the experiments, and filtered immediately before use to remove bacteria). A known amount of fecal pellets (300 to 1500) was transferred from the 
Petri dish to the calorimetric vessel with a mouth pipette, and diluted to a final volume of $3 \mathrm{ml}$ with $0.2 \mu \mathrm{m}$-filtered, stored seawater. This allowed $1 \mathrm{ml}$ atmospheric headspace in the calorimetric vessel. The total handling time was approximately $1 \mathrm{~h}$. The average volume of the fecal pellets was estimated prior to each experiment from inverted microscopy measurements (200× magnification) of their linear dimensions ( $\mathrm{n}=40$ to 50 pellets in each experiment), assuming a cylindrical shape.

Isothermal microcalorimetry. All calorimetric measurements were conducted on Type 2277 thermal activity monitors (TAM) from Thermometric A/B. One instrument was equipped with an amplifier module enabling a resolution of the heat-flow measurements extending into the $\mathrm{nW}$ range, while the other had the standard $\mu \mathrm{W}$ amplifier. No systematic differences between the 2 instruments were detected. The sample was loaded into a $4 \mathrm{ml}$ stainless steel calorimetric vessel and mounted on a Type 2250 perfusion calorimetry module (Thermometric A/B). To thermally equilibrate the sample, it was gradually lowered into the calorimeter over a period of $60 \mathrm{~min}$. At this stage, data collection was initiated and monitored over the subsequent 20 to $24 \mathrm{~h}$. Throughout the thermal equilibration and data acquisition periods, the sample was stirred by a $5 \mathrm{~mm}$ gold propeller at $60 \mathrm{rpm}$ to ensure a constant supply of oxygen to the fecal pellets and a proper exchange of DOC with the surrounding water (sensu Lee \& Fischer 1994). To ensure that the stirring did not cause fecal pellet fragmentation, we checked that no fecal pellets were fragmented at the end of experiments, by observing them under a microscope.

Microbial degradation of fecal pellets. The microbial activity of 300 to 1500 fecal pellets was measured over 20 to $24 \mathrm{~h}$. The microbial activity was also measured in $0.2 \mu \mathrm{m}$-filtered, stored seawater as a control. Furthermore, 3 different control experiments were conducted to ensure that the measured heat actually originated from the microbial degradation of fecal pellet carbon and not from other potential carbon sources; these controls were performed as separate experiments: (1) fecal pellets were washed 3 times on a $45 \mu \mathrm{m}$ filter with $0.2 \mu \mathrm{m}$-filtered, stored seawater to remove remains of DOC and POC of $<45 \mu \mathrm{m}$ from the grazing beaker; (2) the copepods were removed from the grazing beaker to defecate in seawater without food algae to ensure that degradation of carbon from algae adhering to the pellet surfaces did not contribute to the measured heat-flow; (3) heat-flow from the degradation of particles other than fecal pellets (algae, dead copepods, exoskeletons, eggs, etc.) and of water from the grazing beaker was measured to ensure that these potential carbon sources did not contribute any significant heat production.
Factors limiting microbial growth. In some experiments, inorganic nutrients in the form of $\mathrm{NaNO}_{3}$ and $\mathrm{NaH}_{2} \mathrm{PO}_{4}$ were injected after approximately $23 \mathrm{~h}$, to test for $\mathrm{N}$ and $\mathrm{P}$ limitation of microbial activity. We injected $10 \mu \mathrm{l}$ solutions with a concentration of $100 \mathrm{mM}$ $\mathrm{NaNO}_{3}$ and $20 \mathrm{mM} \mathrm{NaH} \mathrm{PO}_{4}$, resulting in initial $\mathrm{NaNO}_{3}$ and $\mathrm{NaH}_{2} \mathrm{PO}_{4}$ concentrations of 0.30 and $0.07 \mathrm{mM}$ in the calorimetric vessel, respectively. These concentrations correspond to 25 and $50 \%$ of the concentrations in the $B_{1}$ media (Hansen 1989), and thus should represent concentrations in excess of those required for microbial growth.

In another experiment, glucose was injected after approximately $23 \mathrm{~h}$ to test if labile DOC-limitation affected microbial growth: $20 \mu \mathrm{l}$ of a $33 \mathrm{mM}$ glucose solution was injected, resulting in an initial glucose concentration of $0.2 \mathrm{mM}$. Lund syringes (Thermometric) were used for injection. The calorimetric vessel contained 300 fecal pellets in each experiment.

Oxic vs. anoxic microbial activity. A sample of 800 fecal pellets was purged with $\mathrm{N}_{2}\left(80 \mathrm{ml} \mathrm{h}^{-1}\right)$ to remove oxygen. To reduce the oxygen tension as much as possible, the calorimetric vessel was purged with $\mathrm{N}_{2}$ both prior to transfer to the calorimeter and during thermal equilibration. The oxygen concentration was measured before and after the experiment with a Unisense oxygen microsensor (OX25), to ensure that no oxygen was present. After removal from the calorimeter, the oxygen concentration was measured to $<0.5 \%$ saturation. This low amount of $\mathrm{O}_{2}$, which is close to the detection level of the electrode, probably reflects uptake of atmospheric $\mathrm{O}_{2}$ during the few minutes when the calorimetric vessel is opened for insertion of the electrode (see 'Discussion'). Microbial activity was measured simultaneously in a sample also containing 800 fecal pellets but under strict oxic conditions.

Oxygen measurement. To assess changes in oxygen concentrations, we conducted parallel experiments using a Unisense oxygen microsensor (OX25). A gastight glass vial with a total volume of $4 \mathrm{ml}$ was filled with $3 \mathrm{ml} 0.2 \mu \mathrm{m}$-filtered, stored seawater containing 500 fecal pellets, and closed with a lid with a teflon membrane. The oxygen microsensor was gently pressed through the teflon membrane, and the oxygen concentration was measured over $24 \mathrm{~h}$ at $18^{\circ} \mathrm{C}$ in complete darkness. To mimic the conditions of the calorimetric measurements, the fecal pellets were kept in suspension by a magnetic stirrer, with a stirring speed of approximately $60 \mathrm{rpm}$.

To ensure that oxygen tension was not limiting aerobic microbial growth, oxygen concentrations were recorded in some experiments in the samples analysed by calorimetry at the end of the calorimetric experiments. This was done by immersing the oxygen 
microsensor in the calorimetric vessel immediately after removal from the calorimeter.

Calculation of specific growth rates of microbial community and degradation rates of fecal pellets. If the heat-flow is assumed to be proportional to the microbial metabolism, and the metabolism is proportional to the biomass of active bacteria, specific growth rates can be calculated by fitting the microbial growth phase to exponential growth (Xie et al. 1988):

$$
P(t)=P_{0} \mathrm{e}^{k t}
$$

where $P(t)$ is the heat-flow at a given time, $t, P_{0}$ is the heat-flow at $t=0$, and $k$ is the specific growth rate $\left(\mathrm{h}^{-1}\right)$.

In contrast to growth rates, calculation of specific degradation rates of fecal pellets rely on several assumptions. Hence, to calculate specific degradation rates, it is necessary to convert the heat-flow signal to an equivalent combustion of organic carbon. This requires an average value for the enthalpy arising from combustion of organic carbon from the fecal pellets. In the present study we assumed that the enthalpic contributions from anabolic processes were neglible compared to catabolic processes. This has been shown to be a reasonable assumption under fully aerobic metabolism, where the degree of reduction of the organic carbon in the substrate and the microbial biomass are comparable (Gustafsson 1991). Specific degradation rates also rely on knowledge of the carbon content of fecal pellets. Hence, the rate of degradation $\left(R_{\mathrm{d}}, \mathrm{h}^{-1}\right)$, may be written as:

$$
R_{\mathrm{d}}=\frac{P M_{\text {carbon }} 3600 \mathrm{~s}}{\Delta H_{\mathrm{C}} m_{\text {carbon }}}
$$

where $P$ represents the heat-flow, $\Delta H_{C}$ is the enthalpy change arising from combustion of organic carbon equivalents, $M_{\text {carbon }}$ is the molar mass of carbon and $m_{\text {carbon }}$ is the mass of organic carbon in fecal pellets at a given time during the experiment; $m_{\text {carbon }}$ is calculated by knowledge of the carbon content at $t=0$ and the total heat evolved at a given time, which is proportional to the amount of fecal pellet carbon remineralized. Thus, $m_{\text {carbon }}$ is calculated by subtraction of the amount of carbon remineralized at a given time from the carbon content at $t=0$. The term $3600 \mathrm{~s}$ is a time conversion factor, to convert from $\mathrm{J} \mathrm{s}^{-1}$ to $\mathrm{J} \mathrm{h}^{-1}$. The carbon content of the fecal pellets to $t=0$ is calculated from literature values of the carbon:volume ratio of fecal pellets and the calculated total volume based on linear measurements and the number of fecal pellets incubated. We used a $\Delta H_{C}$ of $504.19 \mathrm{~kJ} \mathrm{Cmol}^{-1}$ derived from combustion of several different phytoplankton species (Duboc et al. 1999), and 3 different

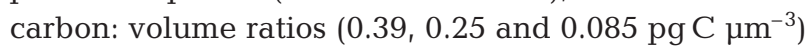
(Hansen et al. 1996, Urban-Rich et al. 1998) (see Table 1).

\section{RESULTS}

The microbial activity associated with the degradation of fecal pellets from the cultivated calanoid copepod Acartia tonsa was successively measured by isothermal microcalorimetry. Fig. 1A shows 3 parallel measurements in which the degradation of 500 fecal pellets was followed over $20 \mathrm{~h}$, with a good reproducibility between the 3 replicates. Microbial activity increased exponentially over the first $10 \mathrm{~h}$, and reached a maximum level, after which it declined and reached a fairly constant level at $20 \mathrm{~h}$. Another (local) maximum level of microbial activity was observed between 14 and $16 \mathrm{~h}$. The intensity of the observed peak varied from day to day, but was reproducible in experiments performed with the same batch of fecal pellets. In general, the degradation pattern was always associated with a peak of microbial activity between 6 and $12 \mathrm{~h}$, after which the activity declined to a constant lower level.

The microbial activity associated with the anoxic degradation of 800 fecal pellets is shown in the inset in Fig. 1A. The measured heat-flow increased from 0 to $1.5 \mu \mathrm{W}$ within $20 \mathrm{~h}$. For comparison, the heat-flow from a sample containing 800 fecal pellets under oxic conditions was measured simultaneously in a different calorimetric channel. The total heat generated $(Q, J)$ within $20 \mathrm{~h}$, was 1 order of magnitude lower under anoxic conditions (0.054) than under oxic conditions (0.50).

Fig. 1B shows the oxygen concentration measured in a parallel sample: there was a moderate decline in oxygen concentration until approximately $12 \mathrm{~h}$, after which it slowly increased. The oxygen concentration is probably controlled by 2 processes: consumption by bacteria and diffusion from the atmospheric headspace. This means that within the first $12 \mathrm{~h}$ consumption exceeds $\mathrm{O}_{2}$ diffusion, and vice versa after $15 \mathrm{~h}$. This also corresponds to the shape of the thermograms, in which a peak in metabolic activity is apparent within this time range. Fig. $1 \mathrm{~B}$ also shows that the oxygen concentration did not fall below $0.18 \mathrm{mM}_{\text {; }}$ this should have ensured oxic conditions suitable for microbial activity, since the $K_{\mathrm{m}}$ (half-saturation constant) for oxygen respiration is approximately $1 \mu \mathrm{M}$ for heterotrophic micro-organisms (Focht \& Verstraete 1977).

Fig. $1 \mathrm{C}$ represents fecal pellet degradation rate as a function of time, calculated from the 3 replicates in Fig. 1A, based on a carbon:volume ratio of $0.39 \mathrm{pg} \mathrm{C}$ $\mu^{-3}$. The degradation rate was low for the first $5 \mathrm{~h}$, with a value of approximately $0.01 \mathrm{~h}^{-1}$; after 10 and $15 \mathrm{~h}$ it peaked at 0.10 and $0.09 \mathrm{~h}^{-1}$, respectively; and towards the end of the experiment decreased to approximately $0.04 \mathrm{~h}^{-1}$. The average degradation rate in Fig. $1 \mathrm{C}$ during the first $20 \mathrm{~h}$ was $0.045 \mathrm{~h}^{-1}$. 
Fig. 1D illustrates the percentage fecal pellet carbon degraded as a function of time from the same series of samples as in Fig. 1A and based on the same carbon:volume ratio. After 20 h, $55 \%$ of the fecal pellet carbon was degraded in this particular data set.

Since the literature provides a large range of carbon:volume ratios for copepod fecal pellets, and since this parameter is critical for the calculation of degradation rates and the percentage fecal pellet carbon remineralized, we used 3 different carbon:volume ratios (Table 1). It is clear that a lower carbon:volume ratio will affect both degradation rate and percentage fecal pellet carbon remineralized, both of which will increase with decreasing carbon:volume ratio. Consequently, for the lowest

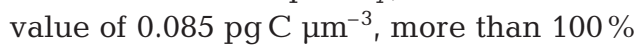
of the fecal pellet carbon would be remineralized according to these calculations. The average $( \pm \mathrm{SD})$ volume of the fecal pellets was $1.83 \times 10^{5} \pm 0.85 \times 10^{5} \mu^{3}$ (n = 401).

Specific growth rates of the microbial communities associated with the fecal pellets were calculated by fitting the growth phase to exponential growth. Table 2 summarizes data of specific growth rates from experiments with a different number of fecal pellets. Based on overlapping standard deviations, no significant relationship was found between the numbers of fecal pellets and the specific growth rates of the microbial communities.

Fig. 2 illustrates the effect of addition of glucose or inorganic nutrients on microbial activity after the exponential growth phase. Microbial activity followed the typical pattern illustrated in Fig. 1 and increased

Table 1. Acartia tonsa. Percent fecal pellet carbon degraded after $20 \mathrm{~h}$ and mean \pm SD degradation rate within $20 \mathrm{~h}$, calculated using 3 different carbon:volume ratios of fecal pellets. Calculations based on 10 experiments with different batches of fecal pellets

\begin{tabular}{|lcc|}
\hline $\begin{array}{l}\text { C:vol } \\
\left(\operatorname{pgC} \mu \mathrm{m}^{-3}\right)\end{array}$ & $\begin{array}{r}\text { \% degraded } \\
\text { after } 20 \mathrm{~h}\end{array}$ & $\begin{array}{c}\text { Degradation } \\
\text { rate }\left(\mathrm{h}^{-1}\right)\end{array}$ \\
\hline $0.39^{\mathrm{a}}$ & $28 \pm 18$ & $0.023 \pm 0.015$ \\
$0.25^{\mathrm{b}}$ & $45 \pm 27$ & $0.047 \pm 0.038$ \\
$0.085^{\mathrm{c}}$ & $128 \pm 84$ & - \\
${ }^{\mathrm{a}}$ Hansen et al. (1996) & & \\
${ }^{\mathrm{b} U r b a n-R i c h ~ e t ~ a l . ~(1998) ~}$ \\
'Value between those of Hansen et al. (1996) and Urban- \\
Rich et al. (1998)
\end{tabular}

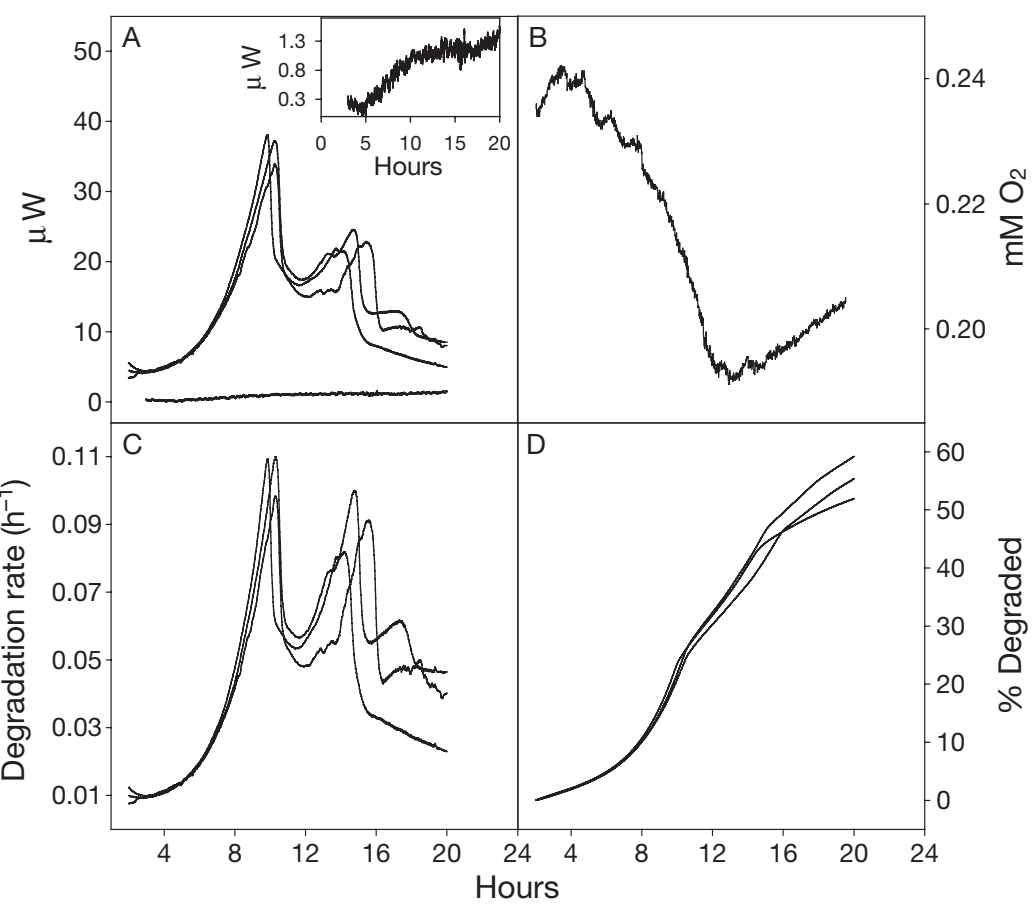

Fig. 1. Acartia tonsa. (A) Heat-flow as a function of time in 3 samples containing 500 fecal pellets at $18^{\circ} \mathrm{C}$ under oxic conditions; the lower line (magnification in inset) represents calorimetric experiment of anoxic egradation of 800 fecal pellets. (B) Oxygen concentration as a function of time in sample parallel to those in (A), with 500 fecal pellets at $18^{\circ} \mathrm{C}$. C) Degradation rates as a function of time, calculated from the 3 samples in (A). (D) Percent total fecal pellet carbon degraded as a function of time, calculated from the 3 samples in (A). See 'Materials and methods' (Eq. 2) for calculation of degradation rates

exponentially, reaching a maximum after approximately $10 \mathrm{~h}$. It then decreased, reaching a constant level after $20 \mathrm{~h}$. Addition of glucose (Fig. 2A) induced a significant increase in microbial activity over a $\sim 6 \mathrm{~h}$ period, followed by an immediate decrease until it reached approximately the same level as before the addition.

In contrast, addition of $\mathrm{N}$ and $\mathrm{P}$ (Fig. 2B) had no obvious effect on microbial activity. The sharp peak immediately after addition of $\mathrm{N}$ and P lasted only for $10 \mathrm{~min}$ and was ascribed to the heat generated by the mixing

Table 2. Acartia tonsa. Mean specific growth rates $(k)$ of microbial community associated with copepod fecal pellets. $\mathrm{n}$ : no of samples; \pm SD shown when $\mathrm{n}>2$

\begin{tabular}{|lccc|}
\hline No. of pellets & Mean $k\left(\mathrm{~h}^{-1}\right)$ & $\mathrm{SD}$ & $\mathrm{n}$ \\
\hline 400 & 0.095 & - & 1 \\
500 & 0.20 & 0.11 & 3 \\
800 & 0.24 & - & 1 \\
1000 & 0.18 & 0.11 & 3 \\
1500 & 0.19 & - & 2 \\
\hline
\end{tabular}




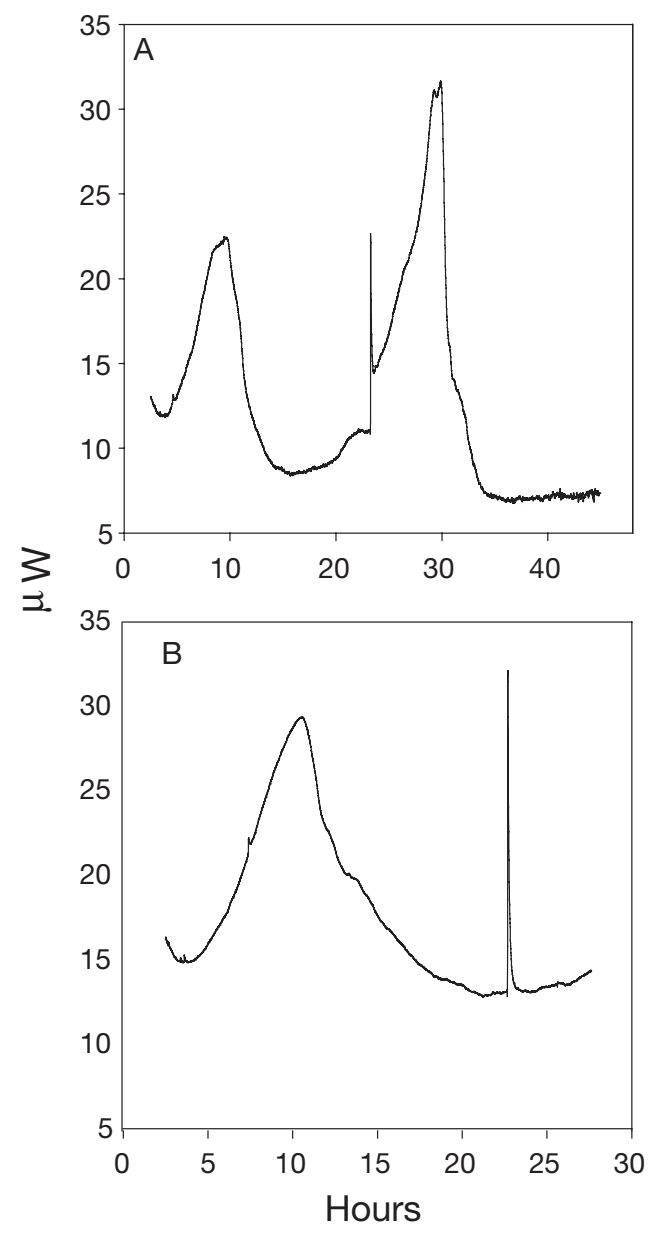

Fig. 2. Acartia tonsa. Effect of addition after $23 \mathrm{~h}$ of (A) $20 \mu \mathrm{l}$ $33 \mathrm{mM}$ glucose and (B) $10 \mu \mathrm{l} 100 \mathrm{mM} \mathrm{NaNO}_{3}$ and $20 \mathrm{mM}$ $\mathrm{NaH}_{2} \mathrm{PO}_{4}$ to a sample containing 300 fecal pellets

of the solutions. The results indicate a DOC limitation controlling microbial growth. These observations were reproducible in 3 different trials with different batches of fecal pellets.

\section{DISCUSSION}

The use of isothermal microcalorimetry to measure microbial growth associated with the degradation of fecal pellets has provided both quantitative and qualitative information on the degradation pattern. Although life processes consist of numerous different metabolic reactions, total heat dispersion represents a bulk measure of the overall metabolism of a system. This 'black box' approach proved useful in attempts to derive specific growth rates of the microbial community, estimate specific degradation rates of fecal pellets, determine limiting factors controlling microbial growth, and compare oxic and anoxic microbial activity.

\section{Microbial activity}

The microbial activity associated with the degradation of 300 to 1500 fecal pellets was always characterized by a peak in microbial activity after approximately $10 \mathrm{~h}$, after which activity declined. The results suggest that labile organic carbon (not $\mathrm{N}$ or P) is the factor limiting microbial activity. Thus, spiking the glucose concentration to $0.2 \mathrm{mM}$ increased the microbial activity to a level comparable to the peak observed around $10 \mathrm{~h}$. We suggest that this peak, with a maximum around $10 \mathrm{~h}$, corresponds to the degradation of labile DOM. This was supported by measurements indicating that around $85 \%$ of the measured heat originated from DOM and/or non-visual POM from the water from the storage Petri dish (Fig. 3). Fig. 3 shows the metabolic heat associated with samples of water from the storage Petri dish with and without fecal pellets. Fig. 3 also shows 2 measurements of the metabolic heat associated with $0.2 \mu \mathrm{m}$-filtered, stored seawater. It is clear that the high thermal activity of the water from the Petri dish does not originate from the $0.2 \mu \mathrm{m}$-filtered, stored seawater, whose thermal activity is near $0 \mu \mathrm{W}$. Thus, the high thermal activity of the water from the Petri dish must originate from DOC associated with the particles flushed from the filter to the Petri dish with $0.2 \mu \mathrm{m}$-filtered, stored seawater. The high activity associated with the water from the Petri dish could raise the question as to whether we were actually measuring the degradation of fecal pellet carbon, or if other carbon sources were present. However, carefully performed control experiments confirmed that no significant difference in heat-flow arose from washing the fecal pellets with $0.2 \mu \mathrm{m}$-filtered, stored seawater 3 times on the filter before flushing them into the Petri dish. This suggests that no contamination with other carbon sources occurred. Furthermore no significant effect was observed for pellets collected from water with or without food algae, indicating no contamination with DOC or POC from algae. Finally, the signal originating from water from the grazing beaker and particles such as eggs and dead copepods only gave rise to a neglible heat-flow, significantly lower than that of samples with fecal pellets. Based on the high thermal activity in the water from the storage Petri dish used during the processing of the pellets, and the control experiments showing that other carbon sources did not contribute significantly to the thermal activity, we conclude that the observed heat-flow indeed reflects microbial degradation of fecal pellet carbon. However, this carbon pool seems to be fairly dynamic, with a fast leakage of DOC from the fecal pellets, as proposed by Jumars et al. (1989), and/or the presence of non-visual POC, as proposed by Olesen et al. (2005). The variation in peak intensity around $10 \mathrm{~h}$ between experiments with differ- 


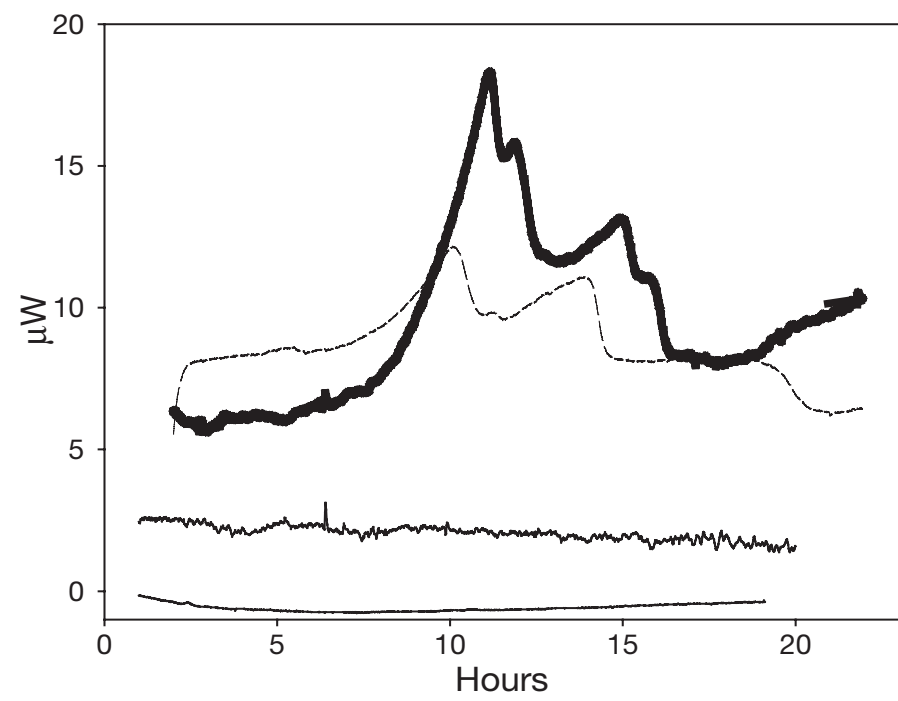

Fig. 3. Acartia tonsa. Difference in heat-flow between samples with same amount of water from storage Petri dish with (continous line) and without (dashed line $85 \%$ of the total signal) 300 fecal pellets. The 2 lines below $5 \mu \mathrm{W}$ represent heat-flow from $0.2 \mu \mathrm{m}$-filtered, stored seawater

ent batches of pellets could thus be due to a variation in the amount of DOC transferred from the Petri dish to the calorimetric vessel.

\section{Fecal pellet degradation rates and microbial growth rates}

Estimation of specific degradation rates was based on literature values for fecal pellet carbon densities and a standard enthalpy of combustion of biological biomass. In the literature, the carbon:volume ratio varies by 1 order of magnitude from 0.02 (Urban Rich et al. 1998) to $0.39 \mathrm{pg} \mathrm{C} \mathrm{mm}^{-3}$ (Hansen et al. 1996). Furthermore the standard enthalpy arising from combustion depends on the exact composition of the fecal pellets (lipids, carbohydrates, hydrocarbons, etc.). At the highest car-

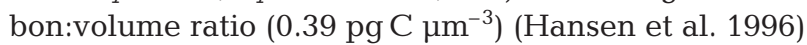
and the chosen standard enthalpy for combustion of $504.19 \mathrm{~kJ} \mathrm{C} \mathrm{mol}^{-1}$ (Duboc et al. 1999), corresponding to the combustion of phytoplankton, we estimated the mean \pm SD specific degradation rate to be $0.023 \pm$ $0.015 \mathrm{~h}^{-1}$. This corresponds to a degradation of $28 \pm$ $18 \%$ of the fecal pellet carbon within the first $20 \mathrm{~h}$.

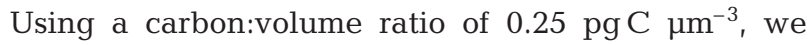
estimated the degradation rate as $0.047 \pm 0.038 \mathrm{~h}^{-1}$, and found that $45 \pm 27 \%$ of the fecal pellet carbon was remineralized within $20 \mathrm{~h}$. The lowest carbon:volume

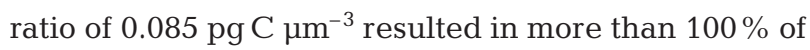
the fecal pellet carbon being remineralized within $20 \mathrm{~h}$. Thus, when using the highest carbon:volume ratio of $0.39 \mathrm{pg} \mathrm{C} \mathrm{mm}^{-3}$ we found a degradation rate 3 to 4 times higher than that recently reported by Thor et al. (2003) for pellets from wild-caught Acartia tonsa. Therefore, measurement of their actual carbon content and the composition of the organic matter in the batch of fecal pellets studied are necessary to ensure more precise values of their degradation rate. Furthermore, a strict control of the DOC pool is needed. Nevertheless, the current results show that calorimetry may be useful in investigations of microbial degradation, particularly in comparative studies, where absolute values of carbon content and combustion heat are of minor importance.

Isothermal microcalorimetry has proved useful in determining specific growth rates of the microbial community associated with copepod fecal pellets. The advantage of this method is that it is possible to determine specific growth rates using 1 sample, without performing batch samples involving counting bacteria (Hansen \& Bech 1996) or isotope incorporation (Thor et al. 2003). Thus, the method is non-invasive, with none of the uncertainty introduced by subsampling. In addition, the real-time registration of the heat-flow provides continuous information, in contrast to counting and radioactive isotopic labelling, whereby sequential subsampling is typically performed at intervals of hours. The microbial growth associated with the fecal pellets showed a typically exponential growth pattern, with specific growth rates within the range of 0.095 to $0.24 \mathrm{~h}^{-1}$. This is quite high compared to the 0.01 to $0.15 \mathrm{~h}^{-1}$ reported by Jacobsen \& Azam (1984) and the $0.008 \pm 0.009 \mathrm{~h}^{-1}$ reported by Hansen \& Bech (1996). The high growth rates suggest a fully active microbial community associated with the nutrient-rich conditions in our culture tanks, in which the copepods were fed to excess.

\section{Anoxic microbial activity}

The measurement of anoxic activity revealed a heatflow 1 order of magnitude lower than that under oxic conditions. On the basis of subsequent electrochemical measurements, we concluded that the observed heatflow did indeed quantify the anoxic microbial activity. Since there is no $100 \%$ guarantee for anoxic conditions, the likelihood of anoxic activity is thus proposed: had oxygen been present, then the total heat evolved during the experiment under oxic conditions would have required a depletion of $10 \%$ oxygen saturation; this is unrealistic, since the oxygen concentration measured in the calorimetric vessel before and after the experiment strongly suggests an oxygen concentration close to zero.

There has been extensive debate in the literature on the presence and role of anaerobic bacteria associated with fecal pellets (Alldredge \& Cohen 1987, Bianchi et al. 1992, Ploug et al. 1997). Model calculations and 
experimental results of Ploug et al. (1997) showed that the presence of anoxic zones depends on the size of the aggregate, whereby fecal pellets from Acartia tonsa are unlikely to host anoxic zones under fully oxic conditions in the surrounding water since the rate of diffusion of oxygen exceeds the rate of consumption within the pellet matrix. In contrast, Karl \& Tilbrook (1994, and references therein) suggested the presence of a contingent of methanogenic bacteria associated with fecal pellets. Likewise, Bianchi et al. (1992) provided evidence for the coexistence of living and active cells of methanogenic and nitrifying bacteria in fresh fecal pellets. These findings suggest a potential anoxic microbial activity in copepod fecal pellets. The results of the present study clearly indicate the presence of anoxic metabolism. However, we were unable to distinguish if the activity originated from strictly anaerobic or facultative anaerobic bacteria.

\section{Experimental conditions}

The major purpose of this contribution was to determine if isothermal microcalorimetry could be used to measure microbial degradation of copepod fecal pellets. Therefore, the main focus was on the methodology and less on the ecological relevance of the actual physical conditions under which the experiments were performed. Thus, the experimental conditions in the present study were far from the environmental conditions prevailing in situ. The 2 basic parameters considered to be quite unrealistic in the present study compared to natural conditions are the very high food concentration (50000 to 100000 algal cells ml ${ }^{-1}$ ) in the grazing chamber and the equally high fecal pellet density (100 to 500 pellets $\mathrm{ml}^{-1}$ ) in the microcalorimeter. It is well known that saturated food concentration leads to a short gut-passage time and densely packed fecal pellets with maximum carbon content (Besiktepe \& Dam 2002). Our reason for incubating the copepods at excess food concentration and at high copepod densities was to reduce the total time between copepod defecation and the calorimetric measurements. In addition, the high copepod density enabled the high production of fecal pellets necessary to obtain sufficient pellets within a period of $1 \mathrm{~h}$. We do not know how the high carbon density of the fecal pellets in the present study affected the degradation pattern compared to pellets with a lower carbon density, and it would be interesting to investigate this topic in future studies using a range of more natural food concentrations.

The high concentration of fecal pellets in the calorimetric samples is another parameter that could have affected the degradation pattern, and we cannot ex- clude the possibility that it affected DOM production and microbial activity. However, we found no correlation between microbial growth rate and the number of pellets incubated (Table 2), although this could be because the substrate for microbial growth was at a saturating level in all our experiments. Finally it could be argued that our experiment did not reflect natural conditions in which copepod fecal pellets continually sink through the water column. In an attempt to achieve this, the experiments were performed with the pellets kept in suspension by stirring with a propeller. The stirring speed was so adjusted that no fragmentation of the fecal pellets occurred. It is not known to what extent the stirring reflected sinking in natural habitats, but it did ensure $\mathrm{O}_{2}$ ventilation and exchange of DOM between the pellets and the media similar to that experienced when pellets sink through the water column.

In summary, we conclude that isothermal microcalorimetry is a valid method for measuring microbial growth and microbial degradation of copepod fecal pellets. It requires few assumptions and calculations to arrive at relevant process rates. However, calculation of degradation rates requires specific knowledge of the standard enthalpy arising from combustion and of the carbon:volume ratio of the actual pellet material. The methodology is also promising insofar as it allows measurement of weak signals originating from anaerobic activity.

Acknowledgements. We thank A. Faarborg for technical assistance, and K. Koop-Jakobsen and B. Kynde for inspiration through their pilot experiments prior to the present study. We also thank 3 unknown reviewers for constructive comments on an earlier version of the manuscript. This work was supported by the Danish National Research Council project no. 21010549 (to B.W.H) and the Carlsberg foundation (to P.W.).

\section{LITERATURE CITED}

Alldredge AL, Cohen Y (1987) Can microscale chemical patches persist in the sea? Microelectrode study of marine snow, fecal pellets. Science 235:689-691

Bathmann UV, Noji TT, Voss M, Peinert R (1987) Copepod fecal pellets: abundance, sedimentation and content at a permanent station in the Norwegian Sea in May/June 1986. Mar Ecol Prog Ser 38:45-51

Battley EH (1987) Energetics of microbial growth. John Wiley \& Sons, New York

Besiktepe S, Dam HG (2002) Coupling of ingestion and defecation as a function of diet in the calanoid copepod Acartia tonsa. Mar Ecol Prog Ser 229:151-164

Bianchi M, Marthy D, Teyssié JL, Fowler SW (1992) Strictly aerobic and anaerobic bacteria associated with sinking particulate matter and zooplankton fecal pellets. Mar Ecol Prog Ser 88:55-60

Butler M, Dam HG (1994) Production rates and characteristics of fecal pellets of the copepod Acartia tonsa under simulated phytoplankton bloom conditions: implications for vertical fluxes. Mar Ecol Prog Ser 114:81-91 
Duboc P, Marison I, Stocker UV (1999) Quantitative colorimetry and biochemical engineering. In: Kemp RB (ed) Handbook of thermal analysis and calorimetry, Vol 4. Elsevier, Amsterdam, p 267-365

Feinberg LR, Dam HG (1998) Effects of diet dimensions, density and sinking rates of fecal pellets of the copepod Acartia tonsa. Mar Ecol Prog Ser 175:87-96

Focht DD, Verstraete W (1977) Biochemical ecology of nitrification and denitrification. Adv Microb Ecol 1:135-214

Gustafsson L (1991) Microbiological calorimetry. Thermochim Acta 193:145-171

Hansen B, Bech G (1996) Bacteria assocated with a marine planktonic copepod in culture. I. Bacterial genera in seawater, body surface, intestines and fecal pellets and succession during fecal pellet degradation. J Plankton Res 18:257-273

Hansen B, Fotel, FL, Jensen NL, Madsen SD (1996) Bacteria associated with marine planktonic copepod in culture. II. Degradation of fecal pellets produced on a diatom, a nanoflagellate or a dinoflagellate diet. J Plankton Res 18:275-288

Hansen PJ (1989) The red tide dinoflagellate Alexandrium tamarense: effect on behaviour and growth of a tintinnid ciliate. Mar Ecol Prog Ser 53:105-116

Hygum BH, Petersen JW, Søndergaard M (1997) Dissolved organic carbon released by zooplankton grazing activitya high quality substrate pool for bacteria. J Plankton Res 19: 97-111

Jacobsen TR, Azam F (1984) Role of bacteria in copepod fecal pellets decomposition: colonization, growth rates and mineralization. Bull Mar Sci 35:495-502

Jumars PA, Penry DL, Baross JA, Perry MJ, Frost BW (1989) Closing the microbial loop: dissolved carbon pathway to heterotrophic bacteria from incomplete ingestion, digestion, and adsorption in animals. Deep-Sea Res 36:483-495

Karl DM, Tilbrook BD (1994) Production and transport of methane in oceanic particulate organic matter. Nature 368: 732-734

Kiørboe T, Møhlenberg F, Hamburger K (1985) Bioenergetics of the planktonic copepod Acartia tonsa: relation between feeding, egg production and respiration, and composition of specific dynamic action. Mar Ecol Prog Ser 26:85-97

Lampitt RS, Noji T, Bodungen B (1990) What happens to zooplankton fecal pellets? Implication for material flux. Mar Biol 104:15-23

Lasson L, Gustafsson L (1999) Calorimetry of microbial processes. In: Kemp RB (ed) Handbook of thermal analysis and calorimetry, Vol 4. Elsevier, Amsterdam, p 367-404

Lee BG, Fisher NS (1992) Decomposition and release of elements from zooplankton debris. Mar Ecol Prog Ser 88:117-128

Lee BG, Fisher NS (1994) Effects of sinking and zooplankton grazing on the release of elements from planktonic debris. Mar Ecol Prog Ser 110:271-281

Martens P, Krause M (1990) The fate of fecal pellets in the north sea. Helgol Meeresunters 44:9-19

Møller EF, Nielsen TG (2001) Production of bacterial substrate by marine copepods: effect of phytoplankton biomass and cell size. J Plankton Res 23:527-536

Møller EF, Thor P, Nielsen TG (2003) Production of DOC by

Editorial responsibility: Fereidoun Rassoulzadegan, Villefranche-sur-Mer, France
Calanus finmarchicus, C. glacialis and C. hyperboreus through sloppy feeding and leakage from fecal pellets. Mar Ecol Prog Ser 262:185-191

Mukhanov V, Rylkova O, Lopukhina O, Kemp RB (2003) Productivity and thermodynamics of marine bacterioplankton: an inter-ecosystem comparison. Thermochim Acta 397: $31-35$

Mukhanov VS, Naidanova OG, Shadrin NV, Kemp RB (2004) The spring energy budget of algal mat community in a Crimean hypersaline lake determined by microcalorimetry. Aquat Ecol 38:375-385

Noji TT (1991) The influence of macrozooplankton on vertical particulate flux. Sarsia 76:1-9

Olesen M, Strake S, Andrushaitis A (2005) Egestion of non-pellet bound fecal material from the copepod Acartia tonsa: implication for vertical flux and degradation. Mar Ecol Prog Ser 293:131-142

Pamatmat MM (2003) Heat-flow measurements in aquatic ecosystems. J Plankton Res 25:461-464

Pamatmat MM, Graf G, Bengtsson W, Novak CS (1981) Heat production, ATP concentration and electron transport activity of marine sediments. Mar Ecol Prog Ser 4:135-143

Ploug H, Kühl M, Bucholz-Cleven B, Jørgensen BB (1997) Anoxic aggregates - an ephemeral phenomenon in the pelagic environment? Aquat Microb Ecol 13:285-294

Smetacek VS (1980) Zooplankton standing stock, copepod fecal pellets and particulate detritus in Kiel Bight. Estuar Coast Mar Sci 2:477-490

Stocker UV, Marison IW (1989) The use of calorimetry in biotechnology. In: Fiechter A (ed) Advances in biochemical engineering. Springer-Verlag Berlin, p 106-115

Stocker UV, Gustafsson L, Larsson C, Marison I, Tissot P, Gnaiger E (1993) Thermodynamic considerations in constructing energy balances for cellular growth. Biochim Biophys Acta 1183:221-240

Støttrup JG, Richardson K, Kirkegaard E, Pihl NJ (1986) The cultivation of Acartia tonsa Dana for use as a live food for marine fish larvae. Aquaculture 52:87-96

Thor P, Dam HG, Rogers DR (2003) Fate of organic carbon released from decomposing copepod fecal pellets in relation to bacterial production and ectoenzymatic activity. Aquat Microb Ecol 33:279-288

Tornblom E (1995) Microbial activity and biomass in aquatic surface sediments: a community level approach. Doctoral dissertation, Institute of Limnology, Uppsala University

Turner JT (2002) Zooplankton fecal pellets, marine snow and sinking phytoplankton blooms. Aquat Microb Ecol 27: 57-102

Urban-Rich J (1999) Release of dissolved organic carbon from copepod fecal pellets in the Greenland Sea. J Exp Mar Biol Ecol 232:107-124

Urban-Rich J, Hansen DA, Roman MR (1998) Analysis of copepod fecal pellet carbon using a high temperature combustion method. Mar Ecol Prog Ser 171:199-208

Xie CL, Tang HK, Song ZH, Qu SS, Liao YT, Liu HS (1988) Microcalorimetric study of bacterial growth. Thermochim Acta 123:33-41

Submitted: November 15, 2004; Accepted: July 5, 2005

Proofs received from author(s): September 5, 2005 